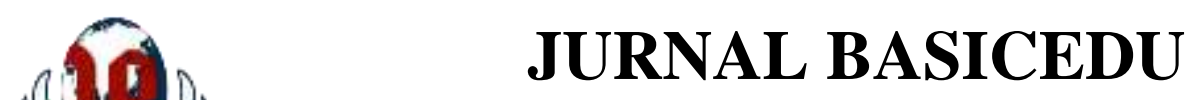

Volume 5 Nomor 6 Tahun 2021 Halaman 5937 - 5945

Research \& Learning in Elementary Education

https://jbasic.org/index.php/basicedu

\title{
Pengembangan Instrumen Asesmen Kinerja Berbasis Literasi Sains pada Pembelajaran Tematik Terpadu Peserta Didik Kelas V Sekolah Dasar
}

\author{
Resty Diana Putri ${ }^{\circledR}$, Herpratiwi ${ }^{2}$, Undang Rosidin ${ }^{3}$ \\ Universitas Lampung, Indonesia ${ }^{1,2,3}$ \\ E-mail: restydianaputri@yahoo.co.id ${ }^{1}$, herpratiwi64@ yahoo.com ${ }^{2}$, $\underline{\text { undangrosidin@ gmail.com }}^{3}$
}

\begin{abstract}
Abstrak
Tujuan penelitian ini adalah mengembangkan instrumen asesmen kinerja berbasis literasi sains yang valid dan praktis pada pembelajaran tematik terpadu peserta didik kelas V Sekolah Dasar. Penelitian pengembangan ini mengikuti tujuh tahap metode Borg and Gall. Subjek penelitian pengembangan ini dibedakan menjadi dua, yaitu subjek uji coba produk adalah validasi ahli dan subjek uji coba pemakaian adalah 30 peserta didik kelas V A SDN 2 Harapan Jaya. Objek dalam penelitian ini adalah instrumen asesmen kinerja berbasis literasi sains pada pembelajaran tematik terpadu kelas V Sekolah Dasar. Data penelitian diperoleh melalui observasi, angket, dan dokumentasi. Hasil penelitian menunjukkan bahwa produk layak digunakan, yang didapat dari rata-rata hasil analisis data oleh validator ahli $85,8 \%$ dengan kriteria sangat layak. Selanjutnya hasil analisis instrumen penelitian diperoleh nilai KMO sebesar 0,560>0,5 bahwa butir penilaian yang diamati pada lembar observasi baik untuk digunakan. Hasil uji reliabilitas cronbach's alpha menunjukkan 0,621>0,5. Maka dapat disimpulkan bahwa instrumen asesmen kinerja berbasis literasi sains telah valid dan sangat praktis digunakan pada pembelajaran tematik peserta didik kelas V Sekolah Dasar.
\end{abstract}

Kata Kunci: asesmen kinerja, literasi sains, pembelajaran tematik terpadu.

\begin{abstract}
The purpose of this study was to develop a science literacy-based performance assessment instrument that was valid and practical in integrated thematic learning for the fifth grader. This research followed the seven stages of the Borg and Gall method. The subject of this research is divided into two, namely the subject of the product is expert validation and the subject of the use trial is 30 students of class V A SDN 2 Harapan Jaya. The object of this research is a science literacy-based performance assessment instrument in integrated thematic learning for the fifth grader. Research data was obtained through observation, questionnaires, and documentation. The results showed that the product was feasible to use, which was obtained from the average results of data analysis by expert validators of $85.8 \%$ with very feasible criteria. Furthermore, the results of the analysis of the research instrument obtained a KMO value of 0.560>0.5 that the assessment items observed on the observation sheet are good to use. The results of the reliability test of Cronbach's alpha showed 0.621>0.5. So it can be concluded that the science literacy-based performance assessment instrument is valid and practical to use in the thematic learning of the fifth grader.
\end{abstract}

Keywords: performance assessment, science literacy, integrated thematic learning.

Copyright (c) 2021 Resty Diana Putri, Herpratiwi, Undang Rosidin

Corresponding author :

Email : restydianaputri@yahoo.co.id

DOI : https://doi.org/10.31004/basicedu.v5i6.1688

ISSN 2580-3735 (Media Cetak)

ISSN 2580-1147 (Media Online)

Jurnal Basicedu Vol 5 No 6 Tahun 2021

p-ISSN 2580-3735 e-ISSN 2580-1147 
5938 Pengembangan Instrumen Asesmen Kinerja Berbasis Literasi Sains pada Pembelajaran Tematik Terpadu Peserta Didik Kelas V Sekolah Dasar - Resty Diana Putri, Herpratiwi, Undang Rosidin DOI: https://doi.org/10.31004/basicedu.v5i6.1688

\section{PENDAHULUAN}

Proses pembelajaran tidak hanya mencakup kegiatan menjelaskan dari pendidik kepada peserta didik. Lebih luas dari itu, proses pembelajaran dimulai dari perencanaan pembelajaran, pelaksanaan pembelajaran, dan evaluasi pembelajaran. Pada evaluasi, pendidik membutuhkan kegiatan penilaian yang berjalan sesuai prosedur dan aspek apa yang akan dinilai. Sistem penilaian/asesmen jika dilaksanakan dengan baik akan mendapatkan hasil belajar sesuai dengan kompetensi masing-masing peserta didik. Lebih jelas disebutkan oleh (Idrus, 2019) evaluasi (penilaian) merupakan alat ukur atau proses untuk mengetahui tingkat pencapaian keberhasilan yang telah dicapai peserta didik atas bahan ajar atau materi-materi yang telah disampaikan, sehingga dengan adanya evaluasi maka tujuan dari pembelajaran akan terlihat secara akurat dan meyakinkan.

Asesmen merupakan hal penting dalam pembelajaran karena asesmen mencakup hasil dari seluruh proses pembelajaran. Asesmen memiliki banyak fungsi yang dapat membantu pendidik untuk mengetahui secara menyeluruh tentang peserta didiknya. Sejalan dengan Hindriana dan Setiawati (2018) mengungkapkan nowadays, there is a tendency of people to think that assessment that is done on students suppose to be able to give holistics information about the students. Pendapat tersebut berarti asesmen yang telah dikerjakan oleh peserta didik dapat memberikan informasi holistik tentang mereka. Sejalan dengan yang dikemukakan oleh (Astuti et al., 2012) bahwa asesmen merupakan suatu bagian yang terintegrasi dengan perencanaan dan proses pelaksanaan pembelajaran. Kondisi riil sekolah dan indikator pembelajaran dalam pencapaian kompetensi inti dan kompetensi dasar menjadi acuan penggunaan berbagai metode dan prosedur asesmen yang digunakan.

Asesmen dilakukan sebagai upaya untuk mengukur tingkat ketercapaian indikator pembelajaran dan mengumpulkan informasi perkembangan belajar siswa pada berbagai aspek. Aspek-aspek yang tercakup dalam asesmen ialah aspek kognitif, afektif, dan psikomotorik. Sejalan dengan hal tersebut (Wahyuni et al., 2018) menyatakan bahwa The assessment shall be carried out in accordance with the objectives of the assessment to be achieved in a given study. Pendapat tersebut berarti bahwa penilaian harus diambil berdasarkan objek penilaian yang akan dicapai dari pembelajaran. (Chabalengula \& Mumba, 2009) menjelaskan bahwa in learning science, an assessment is used to examine and describe students' achievement and process in one or more domains of science. Pendapat tersebut berarti dalam mempelajari pengetahuan, penilaian digunakan untuk mengkaji dan mendeskripsikan pencapaian dan proses siswa dalam satu atau lebih domain pengetahuan. Faktanya, Domain yang masih jarang dalam penilaian adalah domain psikomotor.

Berdasarkan hasil analisis kebutuhan penelitian pendahuluan melalui angket mengenai instrumen asesmen kinerja berbasis literasi sains pada pembelajaran tematik terpadu menunjukkan bahwa pendidik membutuhkan instrumen asesmen kinerja berbasis literasi sains pada pembelajaran tematik yang dapat diterapkan dengan mudah dan sesuai kondisi pembelajaran di sekolah. Informasi yang didapat ialah pendidik sudah mengetahui tentang penilaian psikomotor namun beberapa pendidik belum mengetahui cara penilaiannya sehingga belum menerapkan penilaian psikomotor di kelasnya. Pada penerapannya, terdapat beberapa pendidik yang mengalami kesulitan untuk melakukan penilaian psikomotor khususnya dalam penilaian kinerja. Terkait proses penilaian berbasis literasi sains, beberapa pendidik sudah mengetahui dan sudah melakukan penilaian kinerja berbasis literasi sains, namun masih banyak pendidik kesulitan dalam penilaian menggunakan asesmen kinerja berbasis literasi sains. Padahal menurut Word Economic Forum dalam Desain Induk Gerakan Literasi Sekolah oleh (Kemdikbud, 2019) peserta didik memerlukan 16 keterampilan agar mampu bertahan di abad XXI. Salah satunya ialah keterampilan Literasi Sains. Keterampilan ini mendukung asesmen kinerja agar mampu menggunakan pengetahuan dan prinsip ilmiah untuk memahami lingkungan.

Kemudian dilakukan penelitian pendahuluan lanjutan untuk mengetahui respon peserta didik mengenai implementasi asesmen kinerja yang menunjukkan bahwa peserta didik kelas V SD Negeri 1 Harapan Jaya, SD Negeri 2 Harapan Jaya, dan SD Negeri 1 Sukarame pernah mengerjakan tugas kinerja. Tugas kinerja yang diberikan kepada peserta didik dikerjakan secara mandiri dan kelompok. Tugas yang diberikan telah sesuai 
5939 Pengembangan Instrumen Asesmen Kinerja Berbasis Literasi Sains pada Pembelajaran Tematik Terpadu Peserta Didik Kelas V Sekolah Dasar - Resty Diana Putri, Herpratiwi, Undang Rosidin DOI: https://doi.org/10.31004/basicedu.v5i6.1688

dengan materi yang dipelajari, namun sebanyak $66,7 \%$ peserta didik masih merasa kesulitan untuk mengerjakan tugas kinerja. Sebanyak 91,7\% peserta didik melaporkan hasil/presentasi setelah selesai mengerjakan tugas dan mereka sepakat bahwa tugas kinerja membuat peserta didik lebih menunjukkan kemampuan yang sebenarnya. Kemudian, hasil akhir tugas kinerja yang telah dikerjakan diberi penilaian oleh pendidik untuk ditunjukkan kepada orang tua agar dapat memantau perkembangan kemampuan psikomotor peserta didik.

Berdasarkan analisis kebutuhan pendidik dan peserta didik dapat disimpulkan bahwa asesmen yang diterapkan di sekolah kurang optimal khususnya pada instrumen asesmen psikomotor. Pendidik kesulitan untuk mengembangkan sendiri instrumen asesmen psikomotor. Instrumen asesmen psikomotor akan lebih efektif jika diterapkan pada asesmen kinerja yang berbasis literasi sains, karena asesmen kinerja akan berdampak terhadap perubahan sistem penilaian yang berlaku di sekolah dasar menjadi lebih baik. Seperti yang diungkapkan oleh (Yıldırım \& Orsdemir, 2013) Performance appraisal is one of the highly recommended assessment techniques in physics learning especially for psychomotor domains. Pendapat tersebut merekomendasikan asesmen kinerja untuk menilai domain psikomotor/keterampilan. Penilaian kinerja merupakan salah satu penilaian alternatif yang digunakan pendidik yang difokuskan pada dua aspek pokok yaitu mengobservasi proses saat unjuk keterampilan secara langsung serta evaluasi dari produk yang dihasilkan peserta didik. Sehingga melalui kegiatan unjuk kerja tersebut, pendidik dapat mengetahui apa yang peserta didik pahami dari pembelajaran. Disepakati oleh hasil penelitian (Arhin, 2014)yang menyatakan bahwa Asesmen kinerja mendorong peserta didik untuk memiliki proses pemecahan masalah yang diberikan.

Pada asesmen kinerja, peserta didik akan diarahkan untuk menerapkan pengetahuan yang mereka miliki ke dalam suatu kegiatan. Hal tersebut didukung oleh pengertian asesmen kinerja oleh (Serevina \& Muliyati, 2018) menyatakan Performance appraisal is part of an authentic assessment that are considered able to better quantify the overall results of student learning, because these assessments evaluate the progress of learning not through results but also processes and in various ways. Pendapat tersebut sepakat bahwa asesmen kinerja dianggap mampu mengukur hasil belajar siswa secara keseluruhan, karena penilaian ini mengevaluasi kemajuan belajar bukan hanya melalui hasil tetapi juga proses. (Ramadani et al., 2017) juga mengungkapkan performance assessment merupakan penilaian yang mengharuskan siswa untuk melakukan suatu task yang nantinya task tersebut akan dinilai oleh pendidik menggunakan rubric. Hasil dari rubrik yang telah diisi tersebut dapat berfungsi untuk melihat pengaruh dari proses pembelajaran dan bisa digunakan untuk meningkatkan kinerja pendidik berdasarkan hasil asesmen peserta didik. (Richmond et al., 2019) menyatakan Assessment include improving teacher quality and demonstrating impact on student outcomes, accreditation, program improvement, self-reflection, and social justice-centered instruction. Sehingga jelas terlihat bahwa asesmen berfungsi memberikan timbal balik tidak hanya bagi pengaplikasian pengetahuan yang peserta didik miliki, tapi juga bagi guru dan sekolah.

Pengaplikasian pengetahuan berarti peserta didik mampu mengelola informasi yang diperolehnya dari pembelajaran menjadi pengetahuan yang bermanfaat. Pengelolaan informasi tersebut dimulai dari kegiatan mencari hingga memahami pengetahuan yang didapat dari berbagai sumber. Proses ini biasa disebut sebagai kegiatan literasi. Terdapat beberapa jenis literasi, salah satunya ialah literasi sains. Kemampuan literasi sains diartikan sebagai kemampuan seseorang untuk membedakan fakta-fakta sains dari bermacam-macam informasi, kemampuan untuk mengorganisasi, menganalisis, hingga mengambil keputusan terhadap pilihan yang dihadapinya. Jack Holbrook (Lestari et al., 2020) menyatakan science literacy is a science and understanding of scientific concepts and processes that enable a person to make a decision with the knowledge he has and is able to play an active role in all aspects of life, especially in the field of science he is engaged in. Pendapat tersebut berarti bahwa literasi sains adalah ilmu pengetahuan dan pemahaman konsep dan proses ilmiah yang memungkinkan seseorang mengambil keputusan dengan pengetahuan yang dimilikinya dan mampu berperan aktif dalam semua aspek kehidupan, terutama di bidang sains yang digelutinya. 
5940 Pengembangan Instrumen Asesmen Kinerja Berbasis Literasi Sains pada Pembelajaran Tematik Terpadu Peserta Didik Kelas V Sekolah Dasar - Resty Diana Putri, Herpratiwi, Undang Rosidin DOI: https://doi.org/10.31004/basicedu.v5i6.1688

Proses menghadapi masalah yang dilakukan oleh manusia merupakan penerapan dari pengetahuan yang mereka miliki untuk bertanggung jawab terhadap lingkungan. Sejalan dengan pendapat Jamaluddin dkk (Lestari et al., 2020) yang menyatakan bahwa Science literacy can be interpreted as an understanding of science and its processes, as well as its application to the needs of society. Pendapat tersebut bermakna literasi sains dapat diartikan sebagai pemahaman tentang sains dan prosesnya, serta penerapannya pada kebutuhan masyarakat. Disepakati oleh (Dewi \& Firman, 2019), Keterampilan proses sains dapat disebut keterampilan dari ranah pengetahuan dan keterampilan yang diperuntukkan untuk menyelesaikan permasalahan, pengidentifikasi permasalah, mengumpulkan data, menginterpretasi dan mempersentasi data untuk kegiatan mengkonstruksi pengetahuan baru. Sehingga literasi sains dapat bermakna sebagai pemahaman tentang sains mulai dari menyelesaikan masalah hingga penerapan dalam kehidupan di masyarakat.

Pembelajaran pada kurikulum 2013 saat ini mengarahkan keaktifan peserta didik untuk mampu mengelola pola pikirnya dalam memahami materi pembelajaran, menerapkan sikap spiritual, menerapkan sikap sosial, hingga menerapkan keterampilan. Kurikulum 2013 mencakup semua kompetensi yang meliputi Kompetensi Inti (KI)-1, Kompetensi Inti (KI)- 2, Kompetensi Inti (KI)-3, dan Kompetensi Inti (KI)-4. Keempat aspek tersebut dirangkum dalam suatu pembelajaran tematik yang mencakup beberapa mata pelajaran ke dalam satu pembelajaran. Dijelaskan lebih lanjut oleh Hidayati (Sari et al., 2018) Pembelajaran tematik Sekolah Dasar di Indonesia, berdasarkan kurikulum tematik terpadu 2013 merupakan integrasi antar disiplin, multidisiplin, dan transdisipliner. Pembelajaran tematik di Sekolah Dasar digunakan untuk mengintegrasikan dimensi sikap, pengetahuan, dan keterampilan menjadi satu kesatuan, menggabungkan kompetensi dari beberapa pelajaran dasar untuk dihubungkan satu sama lain sehingga saling memperkuat, dan menghubungkan berbagai mata pelajaran dengan lingkungan di sekitarnya. Hal itu berdasarkan pendapat (Herpratiwi et al., 2019) Students gain knowledge, attitudes, and skills and develop various competencies in the topics in a theme. Hal ini memungkinkan mereka untuk memiliki pengetahuan dan pemahaman topik yang lebih luas, lebih dalam, dan lebih bermakna.

Pembelajaran tematik menggunakan tema-tema yang dekat dengan kehidupan siswa, sehingga pembelajaran dapat lebih bermakna dengan siswa mencari sendiri dan menemukan apa yang akan mereka pelajari. Berdasarkan hasil penelitian yang dilakukan (Khoiriya \& Wardani, 2013) menunjukkan bahwa pembelajaran terpadu sangat memperhatikan kebutuhan anak sesuai dengan perkembangan yang holistik dengan melibatkan secara aktif dalam proses pembelajaran baik fisik maupun emosionalnya. Aktivitas meliputi aktif mencari, menggali, dan menemukan konsep serta prinsip keilmuan yang holistik, bermakna, dan otentik sehingga peserta didik dapat menerapkan perolehan belajar untuk memecahkan masalah-masalah yang nyata di dalam kehidupan sehari-hari.

Berdasarkan hasil analisis kebutuhan, pendidik mengalami kesulitan dalam membuat dan menerapkan tugas kinerja, sehingga mereka membutuhkan instrumen asesmen kinerja yang praktis untuk digunakan dalam pembelajaran tematik terpadu. Peserta didik juga mengungkapkan bahwa tugas kinerja membuat peserta didik lebih menunjukkan keterampilan peserta didik yang sebenarnya sehingga pengembangan instrumen asesmen kinerja berbasis literasi sains ini dapat membantu peserta didik untuk bisa melatih kemampuan unjuk kerja mereka dan akan diketahui hasilnya secara pasti melalui instrumen asesmen kinerja.

\section{METODE}

Penelitian ini menggunakan Penelitian dan Pengembangan atau Research and Development $(R \& D)$. Prosedur pengembangan berdasarkan model Borg and Gall (Jumiati, 2017) yang terdapat sepuluh langkah dalam melaksanakan penelitian pengembangan dengan sedikit penyesuaian sesuai konteks penelitian, namun pada penelitian dan pengembangan ini hanya dilakukan sampai langkah ke tujuh yaitu sebagai berikut: (1) pengumpulan informasi awal, (2) perencanaan, (3) pengembangan bentuk produk awal, (4) uji coba awal, (5) revisi produk awal, (6) uji lapangan untuk produk utama, (7) penyempurnaan produk hasil uji coba. Pelaksanaan 
5941 Pengembangan Instrumen Asesmen Kinerja Berbasis Literasi Sains pada Pembelajaran Tematik Terpadu Peserta Didik Kelas V Sekolah Dasar-Resty Diana Putri, Herpratiwi, Undang Rosidin DOI: https://doi.org/10.31004/basicedu.v5i6.1688

studi pendahuluan dan uji coba instrument asesmen kinerja berbasis literasi sains dilakukan di Kelas V SDN 2 Harapan Jaya, sedangkan proses pengembangan instrument asesmen kinerja berbasis literasi sains dilakukan di kampus Universitas Lampung. Subjek penelitian pengembangan ini dibedakan menjadi dua, yaitu subjek uji coba produk adalah validasi ahli dan subjek uji coba pemakaian adalah 30 peserta didik kelas V A SDN 2 Harapan Jaya. Objek dalam penelitian ini adalah instrumen asesmen kinerja berbasis literasi sains pada pembelajaran tematik terpadu kelas V Sekolah Dasar.

Teknik pengumpulan data pada penelitian pengembangan ini menggunakan teknik nontes. Peneliti turut mengikuti dalam pengumpulan data observasi, angket, dan dokumentasi. Teknik analisis data menggunakan analisis validasi ahli, analsisi respon pendidik dan peserta didik, uji validitas instrumen, dan analisis instrumen penelitian (validitas dan reliabilitas).

\section{HASIL DAN PEMBAHASAN}

Hasil penelitian dan pengembangan instrumen asesmen kinerja berbasis literasi sains pada pembelajaran terpadu peserta didik kelas V Sekolah Dasar mengacu pada model Borg and Gall dan hanya dibatasi sampai langkah ke 7. Adapun hasil penelitian yang dimaksudkan adalah sebagai berikut: (1) Penelitian dan Pengumpulan Informasi, dilakukan dengan studi lapangan berupa analisis kebutuhan, dan studi pustaka dengan mengkaji dari buku-buku maupun sumber- sumber yang relevan; (2) Perencanaan, dilakukan dengan analisis kurikulum yang meliputi penentuan tema yaitu pada Tema 3 (Makanan Sehat) / Subtema 3 (Pentingnya Menjaga Asupan Makanan Sehat), KI, KD, dan indikator tugas kinerja; (3) Pengembangan draf produk, dilakukan dengan menentukan tujuan penggunaan instrumen asesmen kinerja berbasis literasi sains, menentukan kisi-kisi instrumen asesmen kinerja berbasis literasi sains yang memuat mata pelajaran, kompetensi dasar, indikator, materi, dan tugas kinerja, serta menentukan bentuk dan format instrumen mencakup langkah-langkah kegiatan dan pedoman penilaian; (4) Uji coba lapangan awal, produk diserahkan terlebih dahulu kepada tim ahli untuk divalidasi. Validasi ahli dalam pengembangan ini ialah validasi ahli materi, validasi ahli evaluasi, validasi ahli bahasa yang ahli sesuai bidangnya. Lalu penyebaran angket respon pendidik serta peserta didik pada uji coba kelompok kecil; (5) Revisi produk awal, produk yang dikembangkan telah melalui tahap validasi oleh ahli evaluasi, ahli materi, dan ahli bahasa diperbaiki sesuai saran yang diberikan oleh para ahli; (6) Uji coba lapangan utama, dilaksanakan di SD Negeri 2 Harapan Jaya, Kecamatan Sukarame, Kota Bandar Lampung. Uji coba dilakukan pada 30 peserta didik sebagai kelas eksperimen; (7) Penyempurnaan produk hasil uji coba, dilakukan dengan memperbaiki komponen produk yang telah dikembangkan.

Menurut (Fitriadi et al., 2020) Proses penilaian kinerja meliputi tahapan perencanaan, tahapan pelaksanaan, tahapan pemberian nilai, tahap persetujuan, dan tahap laporan. Peneliti melakukan validasi ke beberapa ahli evaluasi, ahli materi, dan ahli bahasa untuk mengetahui kelayakan produk asesmen kinerja yang dikembangkan. Berikut hasil validasi dari beberapa ahli terhadap produk yang dikembangkan:

\section{Tabel 1}

Hasil validasi oleh para ahli

\begin{tabular}{clc}
\hline No & \multicolumn{1}{c}{ Validator } & Nilai \\
\hline \multirow{2}{*}{1} & Ahli Evaluasi 1 & $92,8 \%$ \\
& Ahli Evaluasi 2 & $78,5 \%$ \\
& Ahli Materi 1 & $82,5 \%$ \\
2 & Ahli Materi 2 & $95 \%$ \\
& Ahli Bahasa 1 & $81,3 \%$ \\
3 & Ahli Bahasa 2 & $84,4 \%$ \\
& Rata-rata & $85,8 \%$ \\
& Kriteria & Sangat Layak \\
\hline
\end{tabular}

Hasil validasi oleh para ahli yang menilai rancangan produk instrumen asesmen kinerja berbasis literasi sains telah memenuhi kriteria dengan rata-rata nilai $85,8 \%$ dengan kriteria sangat layak. 
5942 Pengembangan Instrumen Asesmen Kinerja Berbasis Literasi Sains pada Pembelajaran Tematik Terpadu Peserta Didik Kelas V Sekolah Dasar - Resty Diana Putri, Herpratiwi, Undang Rosidin DOI: https://doi.org/10.31004/basicedu.v5i6.1688

Validasi Ahli evaluasi mendapatkan nilai rata-rata sebesar 85,7\%, Aspek instrumen yang meliputi perumusan indikator jelas dan tegas, menggunakan kata tanya dan perintah yang jelas, petunjuk tentang cara penilaian kinerja yang jelas dan mudah digunakan, terdapat pedoman penskoran, terdapat rubrik penskoran proses dan tabel yang terdapat pada instrumen asesmen kinerja sesuai dengan masalah yang ditanyakan.

Validasi ahli materi mendapatkan rata-rata nilai $88,8 \%$. Aspek instrumen asesmen sesuai dengan kompetensi dasar dan indikator pembelajaran serta indikator literasi sains, matreri pada instrumen yang disajikan sesuai dengan kompetensi masalah kehidupan sehari-hari.

Sedangkan pada ahli bahasa mendapatkan nilai sebesar $82,9 \%$, aspek lugas yang meliputi ketepatan struktur kalimat, keefektifan kalimat dan pilihan kata sudah memenuhi kriteria Pada aspek komunikatif disebutkan bahwa keterbacaan pesan, ketepatan penggunaan kaidah bahasa pada instrumen mudah dipahami, Pada aspek tulisan dimana kompoisi ukuran huruf dalam penulisan sudah jelas dan memenuhi kriteria.

Hasil validasi ahli ini didukung oleh penelitian yang dilakukan oleh (Putriadi et al., 2020) yang mendapat hasil berdasarkan pengujian menggunakan rumus diatas, didapati nilai rata-rata hasil validasi $91.3 \%$, maka dapat disimpulkan perdikat perangkat instrumen asesmen kinerja pada praktikum IPA berbasis saintifik sangat valid.

\section{Hasil Uji Kepraktisan}

Uji coba produk diawali dengan uji coba kelompok kecil yang dimaksudkan untuk menguji kepraktisan produk instrumen asesmen berbasis literasi sains pada pembelajaran tematik terpadu peserta didik kelas V Sekolah Dasar. Responden pada uji praktisi pada kelompok kecil ini yaitu 2 pendidik SDN 1 Sukarame dan 2 pendidik SDN 1 Harapan Jaya. Uji coba kelompok kecil dilakukan dengan menjelaskan seputar instrumen asesmen yang dikembangkan, kemudian pendidik diberikan angket.

Hasil uji coba kelompok kecil dapat dilihat aspek yang dinilai oleh pendidik yaitu aspek kemenarikan, kemudahan, dan kebermanfaatan. Masing-masing item pernyataan pada lembar ketergunaan atau kepraktisan skor maksimal 4, sedangkan skor minimal 1. Hasil angket respon pendidik kelompok kecil sebagai berikut:

Tabel 2

Rekapitulasi Respon Pendidik Uji Coba Kelompok Kecil

\begin{tabular}{|c|c|c|c|c|c|c|c|}
\hline \multirow{2}{*}{ No } & \multirow{2}{*}{$\begin{array}{c}\text { Aspek yang } \\
\text { dinilai }\end{array}$} & \multicolumn{2}{|c|}{ SDN 1 Sukarame } & \multicolumn{2}{|c|}{ SDN 1 Harapan Jaya } & \multirow{2}{*}{$\begin{array}{c}\text { Skor } \\
\text { Maksimal }\end{array}$} & \multirow{2}{*}{$\begin{array}{c}\text { Presentase } \\
\text { Skor }\end{array}$} \\
\hline & & Pendidik 1 & Pendidik 2 & Pendidik 1 & Pendidik 2 & & \\
\hline 1 & Kemenarikan & 11 & 11 & 11 & 11 & 12 & $91,7 \%$ \\
\hline & Kemudahan & 12 & 12 & 12 & 12 & 12 & $93,8 \%$ \\
\hline & Kebermanfaatan & 16 & 14 & 15 & 13 & 16 & $91,3 \%$ \\
\hline & Jumlah Skor & 39 & 37 & 37 & 36 & & \\
\hline & Skor Maksimal & 40 & 40 & 40 & 40 & & \\
\hline & Persentase Skor & $97,5 \%$ & $92,5 \%$ & $92,5 \%$ & $90 \%$ & & \\
\hline \multicolumn{2}{|c|}{ Rata-rata Persentase } & \multicolumn{4}{|c|}{$93,1 \%$} & & \\
\hline & Kriteria & \multicolumn{4}{|c|}{ Sangat Praktis } & & \\
\hline
\end{tabular}

Tabel menunjukkan bahwa hasil uji respon pendidik uji coba kelompok kecil untuk uji kepraktisan didapat nilai rata-rata aspek kemenarikan ialah $91,7 \%$, nilai rata-rata aspek kemudahan ialah 93,8\%, dan nilai rata-rata dari aspek kebermanfaatan ialah $91,3 \%$. Sehingga didapat nilai rata-rata dari 4 pendidik dengan persentase $88,75 \%$ termasuk pada kriteria sangat praktis.

Berdasarkan hasil uji kepraktisan tersebut membuktikan bahwa instrumen asesmen kinerja berbasis literasi sains merupakan suatu instrumen asesmen yang praktis untuk digunakan dalam proses pembelajaran. Karena asesmen kinerja dapat membantu pendidik untuk bisa menilai keterampilan peserta didik dengan lebih praktis dan bisa meningkatkan pembelajaran menjadi lebih baik. Disepakati oleh Oloruntegbe (Ramadani et al., 2017) yang mengungkapkan performance assessment is possibly be a meaningful indicator of what students know and what they can do. It is also a change in teaching practices to support effective science learning. Hal 
5943 Pengembangan Instrumen Asesmen Kinerja Berbasis Literasi Sains pada Pembelajaran Tematik Terpadu Peserta Didik Kelas V Sekolah Dasar - Resty Diana Putri, Herpratiwi, Undang Rosidin DOI: https://doi.org/10.31004/basicedu.v5i6.1688

itu berarti bahwa melalui asesmen kinerja dapat membawa perubahan dalam praktik pengajaran untuk mendukung pembelajaran yang lebih efektif.

\section{Hasil Uji Validitas}

Uji validitas dilakukan agar mengetahui kesahihan, valid dan tingkat kepercayaan instrumen. Data dianalisis dengan faktor eksplanatori, namun terlebih dahulu dilakukan uji kecukupan sampel dengan melihat Kaiser Mayor Olkin (KMO) menggunakan SPSS 20. Uji validitas data penilaian kinerja ini terdiri dari 3 variabel yang diberikan pada 30 peserta didik hasil observasi penilaian kinerja peserta didik pada kelas besar. Hasil uji KMO sebagai berikut:

Tabel 3

Tes KMO and Bartlett's

\begin{tabular}{llr}
\hline Kaiser-Meyer-Olkin Measure of Sampling Adequacy. & .560 \\
\hline Bartlett's Test of & Approx. Chi-Square & 17.744 \\
\cline { 2 - 3 } Sphericity & Df & 3 \\
\cline { 2 - 3 } & Sig. & .000 \\
\hline
\end{tabular}

Nilai KMO pada data hasil angket pada peserta didik kelompok besar menunjukkan nilai 0,560>0,5 ini dapat diartikan bahwa butir penilaian yang diamati pada lembar observasi baik untuk digunakan. Nilai Bartlett's Test of Sphericity dengan Chi-Square $17.744>$ df 3 dan Sig.0,000 maka dapat disimpulkan bahwa butir penilaian yang diamati pada lembar observasi valid.

Selanjutnya dianalisis dengan varians total dengan hasil sebagai berikut:

Tabel 4

Total Variance Explained

\begin{tabular}{lrrrrrr}
\hline $\begin{array}{l}\text { Compo } \\
\text { nent }\end{array}$ & \multicolumn{3}{c}{ Initial Eigenvalues } & \multicolumn{3}{c}{$\begin{array}{c}\text { Extraction Sums of Squared } \\
\text { Loadings }\end{array}$} \\
\cline { 2 - 7 } & Total & $\begin{array}{c}\text { \% of } \\
\text { Variance }\end{array}$ & $\begin{array}{c}\text { Cumulative } \\
\%\end{array}$ & Total & $\begin{array}{c}\text { \% of } \\
\text { Variance }\end{array}$ & Cumulative \% \\
\hline 1 & 1.810 & 60.323 & 60.323 & 1.810 & 60.323 & 60.323 \\
\hline 2 & .853 & 28.444 & 88.767 & & & \\
\hline 3 & .337 & 11.233 & 100.000 & & & \\
\hline
\end{tabular}

Pada tabel Total Variance Explained di atas, menunjukkan ada 1 faktor yang terbentuk dari 3 variabel yang dimasukkan. Faktor tersebut memiliki faktor eigenvalue $>1$. Faktor 1 eigenvalue sebesar 1,810 dengan variance $60,323 \%$. Besarnya varians yang mampu dijelaskan oleh faktor baru yang terbentuk adalah $60,323 \%$ sedangkan sisanya dijelaskan oleh faktor lain yang tidak diteliti.

Uji reliabilitas dilakukan agar mengetahui tingkat ketetapan atau konsistensi suatu instrumen mengukur apa yang harus diukur.

Data dianalisis menggunakan cronbach'salpha (KR-20) dengan SPSS 20. Uji reliabilitas data keterampilan kolaborasi dan kepedulian ini terdiri dari 3 variabel yang diujikan pada 30 peserta didik hasil observasi pada kelas besar.

\section{Tabel 5}

Hasil Uji Reliabilitas

\begin{tabular}{cc}
\hline Cronbach's Alpha & $\mathrm{N}$ of Items \\
\hline .621 & 3 \\
\hline
\end{tabular}

Berdasarkan Tabel hasil uji reliabilitas cronbach's alpha pada instrumen asesmen kinerja berbasis literasi sains menunjukkan 0,621 > 0,5 maka dapat disimpulkan bahwa instrumen pada asesmen kinerja reliabel atau konsisten. 
5944 Pengembangan Instrumen Asesmen Kinerja Berbasis Literasi Sains pada Pembelajaran Tematik Terpadu Peserta Didik Kelas V Sekolah Dasar-Resty Diana Putri, Herpratiwi, Undang Rosidin DOI: https://doi.org/10.31004/basicedu.v5i6.1688

Instrumen asesmen kinerja berbasis literasi sains dinyatakan valid untuk menilai kinerja peserta didik. Validitas instrumen asesmen kinerja berbasis literasi sains ini didukung oleh beberapa penelitian yang telah dilakukan sebelumnya (Nugroho \& Rusilowati, 2016) yang menunjukkan hasil pengujian dengan menggunakan analisis faktor exploratori didapatkan nilai KMO sebesar 0.722 yang berarti valid untuk digunakan dengan baik dan.valid dalam menilai kemampuan peserta didik. Dikonfirmasi oleh Menurut (Sa'dijah, 2009) yang menyatakan keunggulan dari penerapan asesmen kinerja antara lain: (1) Pembelajaran dapat lebih efektif karena asesmen kinerja terintegrasi dalam proses pembelajaran. (2) Membantu siswa untuk mengkomunikasikan ide, baik kepada teman, guru, maupun kepada kelas. (3) Lebih lengkap dan valid dalam menilai kemampuan siswa. (4) Mengembangkan pengetahuan dan keahlian siswa karena tidak hanya sekadar memberikan jawaban tetapi juga beserta alasannya. (5) Jawaban bersifat terbuka karena tidak ada jawaban benar atau salah.

\section{KESIMPULAN}

Berdasarkan hasil penelitian dan pengembangan yang telah dilaksanakan dengan judul "Pengembangan Instrumen Asesmen Kinerja Berbasis Literasi Sains Pada Pembelajaran Tematik Terpadu Peserta Didik Kelas V Sekolah Dasar" dapat disimpulkan bahwa: 1). Produk instrumen asesmen kinerja berbasis literasi sains dinyatakan layak berdasarkan validasi ahli evaluasi sebesar $85,7 \%$ dengan kriteria sangat layak, 88,8\% dengan kriteria sangat layak oleh ahli materi, dan $82,9 \%$ dengan kriteria sangat layak oleh ahli bahasa. Hal ini berarti bahwa produk layak digunakan untuk menilai kinerja peserta didik. 2). Produk instrumen asesmen kinerja berbasis literasi sains yang dikembangkan valid untuk digunakan, hal ini dibuktikan dengan hasil validitas nilai KMO pada data hasil angket pada peserta didik kelompok besar menunjukkan nilai 0,560>0,5 ini dapat diartikan bahwa butir penilaian yang diamati pada lembar observasi baik untuk digunakan. Nilai Bartlett's Test of Sphericity dengan Chi-Square $17.744>d f 3$ dan Sig.0,000 maka dapat disimpulkan bahwa butir penilaian yang diamati pada lembar observasi valid. Sedangkan hasil uji reliabilitas cronbach's alpha pada instrumen asesmen kinerja berbasis literasi sains menunjukkan 0,621 > 0,5 maka dapat disimpulkan bahwa instrumen asesmen kinerja reliabel atau konsisten. 3). Produk instrumen asesmen kinerja berbasis literasi sains yang dikembangkan praktis digunakan berdasarkan hasil respon pendidik sebesar 93,5\% dan hasil respon peserta didik sebesar $93,8 \%$. Sehingga dapat disimpulkan bahwa instrumen kinerja berbasis literasi sains praktis digunakan dalam pembelajaran.

\section{DAFTAR PUSTAKA}

Arhin, Ato Kwamina. 2015. The Effect of Performance Assessment-Driven Instruction on the Attitude and Achievement of Senior High School Students in Mathematics in Cape Coast Metropolis, Ghana. Journal of Education and Practice. 6(2). 109-116.

Astuti , Widi Puji., Prasetyo, Andreas Priyono Budi., Rahayu, Enni Suwarsi. 2012. Pengembangan Instrumen Asesmen Otentik Berbasis Literasi Sains Pada Materi Sistem Ekskresi. Lembaran Ilmu Kependidikan. 41 (1). 39-43.

Chabalengula, V., Mumba, F., Hunter, W., Wilson, E. (2009). A model for assessing students' science process skills during science lab work. Problems of Education in the 21 st Century. Problems of Education in the 21st Century. 11(-). 28-36.

Dewi, Mera Putri. Firman. 2019. Pengaruh Lembar Kerja Praktikum Terhadap Keterampilan Proses Sains Siswa Kelas IV Sd. Edukatif : Jurnal Ilmu Pendidikan. 1(3). 170-176

Fitriadi., Marsidin, Sufyarma., Sabandi, Ahmad. 2020. Kebijakan Supervisi Dan Penilaian Kinerja Guru Guna Mewujudkan Kompetensi, Kinerja, Mutu Pendidikan Di Sekolah Dasar Menuju Abad 21. Edukatif : Jurnal Ilmu Pendidikan. 2(2). 187-193 
5945 Pengembangan Instrumen Asesmen Kinerja Berbasis Literasi Sains pada Pembelajaran Tematik Terpadu Peserta Didik Kelas V Sekolah Dasar - Resty Diana Putri, Herpratiwi, Undang Rosidin DOI: https://doi.org/10.31004/basicedu.v5i6.1688

Herpratiwi. Erni, M. Astuti, Nelly. Qomario. 2019. The Implementation of A Thematic Team Games Tournament - Cooperative Learning In The Fifth Grade Of Elementary School In Lampung Province. International Journal Of Innovation, Creativity And Change. 9(11). 192-205

Hindriana, Anna Fitri. Setiawati, Ina. 2018. The Development Of Authentic Assessment Rubric For Assessing Undergraduate Students' Learning And Performance. Indonesian Journal Of Learning And Instruction. 1(1). 21-28

Idrus, L. (2019). Evaluasi dalam Proses Pembelajaran. Jurnal Manajemen Pendidikan Islam. 9(2). 920-935

Jumiati, Rochmiyati, Een Y. Haenilah. 2017. Pengembangan Model Asesmen Kinerja Siswa Kelas V Pada Pembelajaran Terpadu Berbasis Literasi Sains. Pedagogi: Jurnal Pendidikan Dasar. 6(4). 1-12.

Kemdikbud. 2019. Desain Induk Gerakan Literasi Sekolah. Jakarta: Direktorat Jenderal Pendidikan Dasar dan Menengah Kementerian Pendidikan dan Kebudayaan.

Khoiriya, Rika Mellyaning., Wardani, Indah Setyo. 2017. Asesmen Autentik Pada Pembelajaran Terpadu Di Sekolah Dasar. Widyagogik. 4(2). 155-174

Lestari, Hana., Setiawan, Wawan., Siskandar, Ridwan. 2020. Science Literacy Ability of Elementary Students Through Nature of Science-based Learning with the Utilization of the Ministry of Education and Culture's "Learning House". Journal of Research in Science Education. 6(2). 215-220.

Nugroho, Bagus Setyo., Djuniadi., Rusilowati, Ani. 2013. Pengembangan Penilaian Kinerja Menggambar Teknik Potongan Di Smk Pada Kurikulum 2013. Journal Of Educational Research And Evaluation. Pengembangan Penilaian Kinerja Menggambar Teknik Potongan di SMK Pada Kurikulum 2013. 5(1).

Putriadi, Desak Nyoman., Suastra, I Wayan., Adnyana, Putu Budi. 2020. Pengembangan Asesmen Kinerja Pada Praktikum Ipa Berbasis Pendekatan Saintifik Dalam Meningkatkan Kemampuan Berpikir Kritis Siswa Kelas Vii Smp. Wahana Matematika dan Sains: Jurnal Matematika, Sains, dan Pembelajarannya. 14(2). 125-143.

Ramadani, Marina., Supahar S., Rosana, Dadan. 2017. Validity of Evaluation Instrument on the Implementation of Performance Assessment to Measure Science Process Skills. Jurnal Inovasi Pendidikan IPA. 3(2). 180188.

Richmond, Gail., Salazar, María Del Carmen., Jones, Nathan. 2019. Assessment And The Future Of Teacher Education. Journal Of Teacher Education. 70(2). 86-89.

Sari, Novika Auliyana., Akbar, Sa'dun., Yuniastuti. 2018. Penerapan Pembelajaran Tematik Terpadu di Sekolah Dasar. Jurnal Pendidikan: Teori, Penelitian, dan Pengembangan. 3(12). 1572-1582.

Sa'dijah, C. 2009. Asesmen Kinerja Dalam Pembelajaran Matematika. Jurnal Pendidikan Inovatif. 4(2), $92-$ 95.

Serevina, V., Muliyati, D. 2018. Development of student performance assessment based on scientific approach for a basic physics practicum in simpleharmonic motion materials. Journal of Physics: Conference Series. 1013(012051). 1-8.

Wahyuni, Vera., Kartono., Susiloningsih, Endang. 2018. Development Of Project Assessment Instruments To Assess Mathematical Problem Solving Skills On A Project-Based Learning. Journal Of Educational Research and Evaluation. 7(2). 147-153.

Yildirim R., Orsdemir E. 2013. Performance Tasks as Alternative Assessment for Young EFL Learners: Does Practice Match the Curriculum Proposal?. International Online Journal of Educational Sciences. 5(3). 